\title{
Côme Alexandre Collini, Mon séjour auprès de Voltaire
}

\section{Olga Penke}

\section{Q OpenEdition}

10 Journals

\section{Édition électronique}

URL : http://journals.openedition.org/studifrancesi/5642

DOI : 10.4000/studifrancesi.5642

ISSN : 2421-5856

Éditeur

Rosenberg \& Sellier

\section{Édition imprimée}

Date de publication : 1 septembre 2011

Pagination : 413-414

ISSN : 0039-2944

\section{Référence électronique}

Olga Penke, "Côme Alexandre Collini, Mon séjour auprès de Voltaire », Studi Francesi [En ligne], 164 (LV I

II) | 2011, mis en ligne le 30 novembre 2015, consulté le 10 janvier 2021. URL : http://

journals.openedition.org/studifrancesi/5642 ; DOI : https://doi.org/10.4000/studifrancesi.5642

Ce document a été généré automatiquement le 10 janvier 2021.

\section{(c) (i) (9)}

Studi Francesi è distribuita con Licenza Creative Commons Attribuzione - Non commerciale - Non opere derivate 4.0 Internazionale. 


\title{
Côme Alexandre Collini, Mon séjour auprès de Voltaire
}

\author{
Olga Penke
}

\section{RÉFÉRENCE}

CÔME ALEXANDRE COLLINI, Mon séjour auprès de Voltaire, édition présentée et annotée par

Raymond Trousson, Paris, Honoré Champion, 2009 («Bibliothèque des correspondances, mémoires et journaux», 57), 269 pp.

1 Secrétaire et témoin quelquefois unique de l'une des périodes particulièrement fécondes de l'écriture de Voltaire, le florentin Cosimo Alessandro Collini (1727-1806), l'auteur de ce livre vit avec le philosophe entre le 10 avril 1752 et le 12 juin 1756. Les lieux de résidence et les tâches qu'il doit remplir changent au cours de cette période: il est copiste, correcteur des épreuves, mais aussi compagnon intellectuel pour lui à Berlin, Potsdam, Francfort, Strasbourg, Colmar, Prangins et aux Délices. Il devient son soutien dans la lutte avec Frédéric II, son confident fidèle pour négocier avec les imprimeurs le rythme de l'impression de ses livres ou la suppression des éditions pirates. L'intention de Collini a été respectée dans cette édition qui publie les textes réunis par lui-même (pour la publication envisagée en 1803, mais réalisée seulement en 1807, après sa mort): Relation de mon séjour auprès de Voltaire (pp. 39-162), Lettres inédites de Voltaire (pp. 163-224) et Notes (p. 225-254). En dehors des mémoires de Collini, le lecteur y trouve sa correspondance avec Voltaire à partir de 1758 jusqu'en 1778, et plusieurs documents précieux qui révèlent la vie intime, les relations humaines, la manière de travailler du philosophe ainsi que beaucoup de détails précieux concernant la genèse des œuvres historiques et dramatiques de Voltaire. Parallèlement à ce témoignage, les mémoires de Collini présentent sa propre vie: la carrière d'un jeune homme italien, digne d'être connue aussi pour elle-même. Il quitte très jeune Florence, trouve sa place dans la vie intellectuelle européenne, parle plusieurs langues. Les ouvrages qu'il écrit témoignent de ses compétences surtout dans le domaine de l'histoire et des sciences naturelles (leur liste se trouve dans la bibliographie). Doué 
d'une souplesse de caractère qui le fait aimer à Voltaire, il démontre aussi une assiduité exceptionnelle dans le travail, dans une période où l'écrivain français pense à mettre au net son œuvre et comble de travail son copiste. Nous ne pouvons qu'admirer son sens de soumission: il accepte sans murmurer les critiques et s'attribue même la responsabilité de la séparation. Voltaire apprécie son travail, l'appelle son cher ami, utilise pour lui un ton bien tendre dans leurs conversations et dans ses lettres. C'est grâce à sa recommandation que Collini deviendra finalement «secrétaire intime» et «historiographe» de l'Électeur palatin Charles-Théodore jusqu'à sa mort.

2 L'édition critique contient une introduction bien riche et des notes savantes qui permettent de lire ces documents précieux en découvrant à la fois la vie quotidienne laborieuse du célèbre écrivain et celle d'un jeune homme qui connaît sa place: moitié domestique moitié confident et ami, dont le dévouement à l'égard de sa tâche est toujours à son comble. En même temps, c'est une lecture passionnante et pleine d'informations variées sur la vie intellectuelle du siècle. Les textes originaux sont très bien commentés et complétés par les références aux ouvrages divers de Voltaire et en particulier à ses correspondances et écrits autobiographiques. Les notes de la première édition sont gardées, mais soigneusement distinguées de celles de la présente publication. Le volume est également fourni d'une bibliographie et d'un index. La maison d'édition Honoré Champion a enrichi nos connaissances sur la vie de Voltaire par ce précieux deuxième document contemporain, après les Anecdotes sur la vie privée de M. de Voltaire de Longchamp, publié en 2009 dans la même collection, et présentées dans «Studi Francesi» (cfr. n. 160, p. 152). 